\title{
MECHANISMS OF INTERACTION OF RADIATION WITH MATTER
}

\author{
PROGRESS REPORT
}

DOE/ER/6D405-7

DE92 040841

Period: July 1, 1991 - August 31, 1992

\section{Nicholas E. Geacintov and Martio Pope \\ Chemistry Department \\ Radiation and Solid State Laboratory}

29 Washington Place

New Yort University

New York, NY 10003

This Report was prepared as an account of work sponsored by the United States Government, Neither the United States nor the Department of Energy, nor any of their employees, nor any of their contractors, subcontractors, or their employees, makes any warranty, express or implied, or assumes any legal responsibility for the accuracy, completeness, or usefulness of any information, apparatus, product or process disclosed or represents that its use would not infringe privately-owned rights.

August 31, 1991

Prepared for: The U.S. Department of Energy

Office of Health and Environmental Research

AGREEMEN'T No. DE-FGO2-86ER-60405 


\begin{abstract}
Fossil fuel and nuclear power generating plants give rise to byproducts which pollute
\end{abstract} our environment and represent potential hazards to human health. These agents include ionizing radiation and the potentially highly toxic, mutagenic, and carcinogenic polynuclear aromatic (PNA) compounds. This project is concerned with studies of biological activitystructure relationships in which the mechanisms of interaction of ionizing radiation and PNA compounds with DNA, the genetic material of the cell, are being investigated and compared. Emphasis is on the following topics: (1) effects of DNA conformation on its mechanisms of interaction with ionizing radiation, (2) the influence of structure and stereochemistry of PNA metabolites on mechanisms of DNA damage, and (3) influence of DNA conformation on interactions between PNA metabolites and DNA molecules, and the structures of the complexes and adducts which are formed. One basic theme of this project is the use of photoexcited states of PNA and nucleic acids as probes of these interactions. In part 1 of this report, recent progress on elucidating the structures of selected PNA-oligonucleotide model adducts by high resolution NMR and gel electrophoresis techniques is summarized. It is shown that the stereochemical properties of benzo[a]pyrene diol epoxide-DNA adducts play a crucial role in determining their interactions with certain enzymes (exonucleases). These results provide useful models for deriving a better understanding of differences biological activities of PNA compounds and the relationships between mutagenicities and the structural properties of PNA-DNA adducts. In part II of this report, a new time-resolved method based on picosecond laser pulse techniques for elucidating the electronic levels involved in electron photoemission and electron transfer in PNA and nucleic acid solids is described. 


\section{TABLE OF CONTENTS}

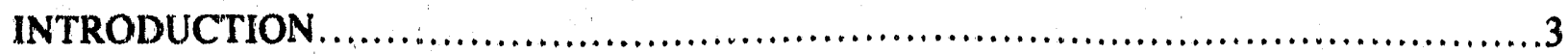

Rationale of Project.............................................................. 3

Current Research Goals and Summary of

Key Progress............................................................. 4

Outline of this Progress Report.....................................................6

PART I. STRUCTURE FUNCTION RELATIONSHIPS:

STRUCTURE AND BIOCHEMICAL CHARACTERISTICS OF POLYNUCLEAR AROMATIC DIOLEPOXIDE-

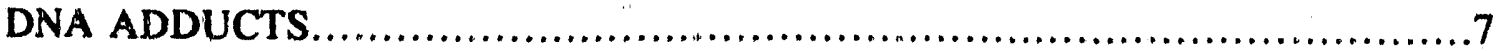

A. Structures of Mutagenic PNA-Nucleic Acid Lesions............................8

1. Synthesis of Stereospecific and Site-Specific benzo[a]

pyrene diolepoxide-oligonucleotide adducts................................... 8

2. Studies of Solution Structure of BPDE-DNA Adducts

by High Resolution NMR Techniques.......................................10

B. Interactions of Enzymes with Sterically Different

Benzola]pyrene Diolepoxide-Oligonucleotide Adducts.

1. Enzyme digestion kinetics of stereochemically different BPDE- DNA Adducts.

2. Unusual hinged bends at BPDE-DNA lesion sites

revealed by enzymatic ligation of modified

oligonucleotides

PART II. TIME-RESOLVED LASER PULSE SPECTROSCOPY FOR PROBING ELECTRONICALLY EXCITED STATE INTERMEDIATES IN POLYNUCLEAR AROMATIC PARTICULATES..................................................... 30

PUBLICATIONS ACKNOWLEDGING THIS GRANT $(1991 / 1992) \ldots \ldots \ldots \ldots \ldots \ldots \ldots \ldots 40$ 


\section{INTRODUCTION}

\section{Rationale of Project}

The production of energy in nuclear power plants or by the combustion of fossil fuels poses a serious potential hazard to human health and the environment. The interaction of ionizing radiation with biological systems, especially cellular DNA, has long been of great concern. The combustion of fossil fuels gives rise to environmental pollutants, including airborne particulates containing deposits of radionuclides and of polynuclear aromatic (PNA) derivatives, many of which are potent mutagens and tumorigens.

This project is concerned with the mecharisms by which these byproducts of modern energy-producing technologies damage DNA, the genetic material of the cell. Such information may ultimately be important for addressing the adverse health effects associated with these environmental pollutants. Of special interest are structure/function/activity relationships which can provide insight into the fundamental mechanisms of these important chemical, physical and biophysical processes.

Studies of biological activity-structure relationships are approached from different points of view, recognizing that both the structure of the DNA as well as the structure and characturistics of the PNA compounds are of critical importance in determining the endpoints of their interactions. A basic theme throughout this work is the use of the photoexcited states of PNA compounds as probes of these interactions. A unique feature of our approach is the characterization of the mechanisms of energy dissipation, photoionization, photoinduced electron Iransfer, and fluorescence of a few key PNA model compounds, and the applications of these phenomena to studies of PNA-DNA interactions. Recently, our repertoire of 
techniques has been extended to one- and two-dimensional NMR, high resolution gel electrophoresis, and biochemical aspects of enzymology.

\section{CURRENT RESEARCH GOALS AND SUMMARY OF KEY PROGRESS}

While most PNA compounds are generally inert and unreactive, in living cells they are metabolized to highly reactive and unstable intermediates which are known to react and bind with the genetic material of the cell. For example, the widely studied PNA compound benzo[a]pyrene is metabolized to different diolepoxide stereoisomers, some of which bind to cellular DNA and are highly mutagenic and carcinogenic. Recent developments and our success in synthesizing large quantities of well-defined benzo[a]pyrene diol epoxide-DNA minihelices for NMR structural studies have been most exciting. We have so far characterized two stereochemically different adducts by high resolution NMR techniques, and compared these structures with their biological characteristics based on their interactions with selected enzyme systems. We believe that this is the first step towards building up our knowledge of chemical structure-biological activity relationships, which will ultimately lead to a more profound understanding of the adverse health effects associated with mutagenic energy-related chemicals. The specific research goals emphasized within the last year are listed below.

(1) Synthesis of Stereospecific and Site-Specific PNA-DNA Adducts and Determination of Structure by NMR Methods.

Developments of methods and elucidation of the aqueous solution structures of PNADNA adducts derived from the covalent binding of a benzo[a]pyrene metabolite to mini-DNA 
double helices. The structures of these lesions are of great significance for an understanding of the mechanisms by which PNA metabolites induce mutations in living systems.

(2) Physica-Chemical Structure-Biological Activity Relationships.

Development of biochemical techniques for studies of tertiary structural characteristics and biological function of site-specific and stereospecific PNA-DNA complexes. By studying the interactions of various enzymes with short segments of altered DNA, insight into structure/function relationships can be obtained.

\section{(3) Structural Effects in DNA Damage Induced by Ionizing Radiation.}

The mechanisms and patterns of damage produced by different types of ionizing radiation (neutrons and gammas) and chemical agents (hydroxyl radicals) are being investigated using short DNA segments (deoxyoligonucleotides) containing specialized structures often encountered in vivo (loops, hairpins, Halliday junctions). This area of research has been relatively neglected and little is known about the effects of ionizing radiation when DNA is not in its usual single-stranded, and double-stranded Watson-Crick form. High resolution gel electrophoresis methods are employed in this work.

\section{(4) Fundamental Characteristics and Physicochemical Characteristics of PNA} Compounds.

Photophysical investigation of photoionization, photoinduced electron transfer, and fluorescence mechanisms in PNA-DNA complexes. These properties act as highly useful probes of the interactions of the bulky PNA aromatic residues with adjacent nucleic acids.

(5) Mechanisms of Non-Linear Photoionization Processes in PNA Solids and Biological Materials: Time-Resolved Dowble-Pulse Picosecond Laser Studies. 
During the last year a new and original method was developed for measuring the lifetimes of short-lived excited states which are involved in non-linear photoionization mechanisms in PNA solids. This method will be useful for specifying the energy levels involved in the ionization of hydrated nucleic acids. These phenomena are critical for the understanding of van der Waals PNA-nucleic acid interactions, in which electrostatic effects are believed to be of great importance.

\section{OUTLINE OF THIS PROGRESS REPORT}

In Part I of this report, we summarize our recent progress on topics (1) and (2), structure-function relationships of PNA-DNA adducts. In Part II, a complete summary of our recent work on picosecond laskr time-resolved photoionization techniques is provided (topic 5); the results of this work have been submitted for publication in the Journal of Physical Chemistry. Results dealing with topics (3) and (4) are not explicitly described here, because recent progress on topic (3) will soon appear in print', while our recent progress on topic (4) has just been published ${ }^{2}$, or will appear in print within the next few months ${ }^{3}$.

1"High-resolution gel electrophoresis methods for studying sequence-dependence of radiation damage and effects of radioprotectants in deoxyoligonucleotides." B. Mao, C.E. Swenberg, Y. Vaishnav, and N.E. Geacintov, in: Biological Effects and Physics of Solar and Galactic Cosmic Radiation, Proceedings of NATO-ASI Conference, Armacao de Pera, Portugal, October 1991, eds. C.E. Swenberg, G. Horneck and E.G. Stassinopoulos, Plenum Press, 1992, to be published.

2"Photoinduced electron transfer and fluorescence mechanisms in covalently linked polynuclear aromatic-nucleotide complexes." N.E. Geacintov, B. Mao, L.L. France, R. Zhao, J. Chen, T.-M. Liu, N.-Q. Ya, L.A. Margulis and J.C. Sutherland (1992), SPIE Proceedings, Time-Resolved Laser Spectroscopy in Biochemistry III, Vol. 1640, 774-783.

3"Identification and quantitative detection of isomeric benzo[a]pyrene diolepoxide-DNA model adducts by low temperature conventional fluorescence techniques." R. Zhao, T.-M. Liu, S.K. Kim, M.C. Macl.eod, and N.E. Geacintov (1992) Carcinogenesis 17, 000-000. 
PART I

STRUCTURE-FUNCTION RELATIONSHIPS: STRUCTURE AND BIOCHEMICAL CHARACTERISTICS OF POLYNUCLEAR AROMATIC DIOL EPOXIDE-DNA ADDUCTS. 


\section{A. STRUCTURES OF MUTAGENIC PNA-NUCIEIC ACID LESIONS.}

In vivo, the ubiquitous PNA pollutant benzo[ajpyrene is metabolized to a large number of oxygenated derivatives, including the chemically highly reactive, and biologically active diol epoxide derivative 7,8-dihydroxy-9,10-epoxy-benzo[a]pyrene (BPDE). There are four different stereoisomers of BPDE, each exhibiting different mutagenic activities. We are particularly interested in the anti-BPDE diastereomer which can be resolved into the $(+)$ and (-)-enantiomers shown in Fig. 1. There are striking differences in the biological activities of these two stereoisomers:

(a) (+)-anti-BPDE is highly tumorigenic while (-)-anti-BPDE is not (1).

(b) (+)-anti-BPDE is more mutagenic than (-)-anti-BPDE in mammalian cell systems, while the (-)-enantiomer is more mutagenic than ( +$)$-anti-BPDE in bacterial cell systems (2). These fascinating differences are believed to be related to the conformations of the different covalent DNA adducts which are formed, and to the processing of these lesions by the enzymatic machineries of bacterial and mammalian cells. Obviously, the processing of these adducts must be quite different in eukaryotic and prokaryotic systems. Within the last project year we have sought to develop methods for (a) synthesizing, (b) studying the conformations of stereospecific and site-specific BPDE-DNA adducts, and (c) studying the interactions of these DNA adducts with selected enzymatic systems.

\section{Synthesis of stereospecific and site-specific benzo[a]pyrene diol epoxide-} oligonucleotide adducts.

We have recently developed efficient and rapid methods for the synthesis, purification, 


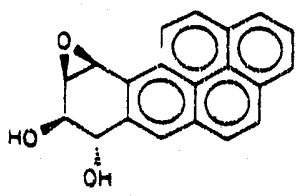

(-) BPDE

WEAK TUMORIGEN

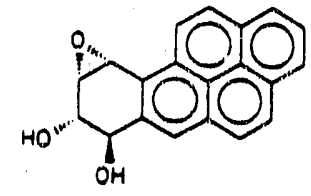

(+) BPDE

STRONG TUMORIGEN

Fig. 1

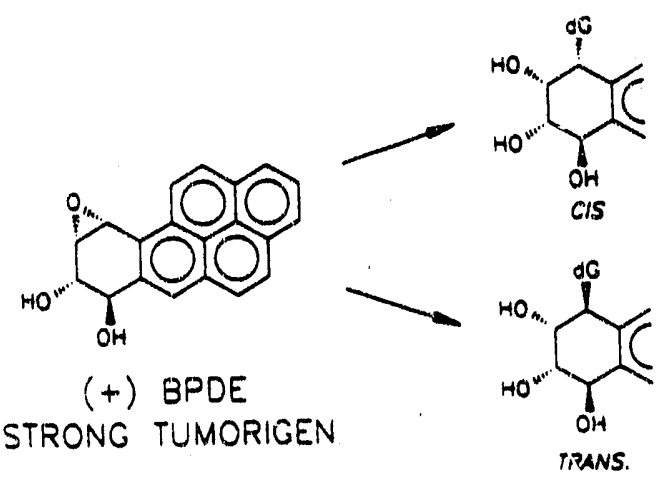

Fig. 2 
and characterizations of adducts derived from the binding of BPDE to deoxyoligonucleotides of defined base composition and sequence $(3,4)$. Both enantiomers of anti-BPDE bind predominantly to the exocyclic amino groups of guanine and adenine in DNA (5). This reaction can proceed either by a trans-addition, or by a cis-addition of the C10 position of BPDE to $\mathrm{N}^{2}$ of the deoxyguanosyl (dG) or $\mathrm{N}^{6}$ of the deoxyadenosyl (dA) moieties in DNA. These two reaction pathways are depicted for the case of dG in Fig. 2. We have found that the cis- and trans-addition adducts have very different conformations (4). It is therefore likely that their biological endpoints will also be different, and the studies of these different adducts is therefore of great interest for understanding structure-biological activity relationships.

\section{Studies of Solution-Structure of BPDE-DNA Adducts by High Resolution}

\section{NMR Techniques.}

We have been able to synthesize a variety of stereospecific and site-specific deoxyoligonucleotides containing one, two or three dG's in an oligomer 9-22 bases long and modified at $\mathrm{N}^{2}$ of $\mathrm{dG}$. Within the last year, we have synthesized the following two adducts in mg quantities and successfully characterized their structures, complexed with their natural complementary strands to form mini-helices, in aqueous solutions by NMR techniques $(6,7)$ :

(I) $d\left(C C A T C G^{(+)-- \text {- } P D D E} C T A C C\right)$

(II) $\mathrm{d}\left(\mathrm{CCATCG}{ }^{(-)+\text {-BPDE}} \mathrm{CTACC}\right)$

The symbols (+)-t-BPDE and (-)-t-BPDE denote adducts derived from trans-addition of (+)-anti-BPDE and (-)-anti-BPDE, respectively, to the exocyclic $\left(\mathrm{N}^{2}\right)$ amino group of 
guanine. The NMR results were obtained in collaboration with Dr. D. Patel's laboratory at Columbia University and are described in the two papers which were published this year $(6,7)$. Here, we provide a brief summary of the key results:

(1) In both double-stranded mini-helices, all 11 hydrogen bonds are intact at $5{ }^{\circ} \mathrm{C}$ and of the Watson-Crick type. This shows that the binding of $(+)-$ and (-)-anti-BPDE to the exocyclic amino group of guanine via trans-addition (Fig. 2), does not significantly perturb the B-type structure of DNA.

(2) In both modified oligonucleotides I and II, the pyrenyl residue is located in the minor groove, with one of its faces exposed to the aqueous solvent environment. In order to accommodate the bulky pyrenyl residue, the minor groove is somewhat widened as compared to unmodified DNA.

(3) The most significant difference between adducts I and II is that in the (+)-antiBPDE-DNA adduct the pyrene ring system points towards the 5'-end of the modified strand, while in the case of the (-)-anti-BPDE adduct it points toward the opposite, 3'-end. Stereoviews of these two structures are shown in Fig. 3.

While all other structural aspects of the adducts I and II appear to be similar, the differences in the orientations of the pyrene ring systems could account for the differences in the mutagenic potentials of the two BPDE enantiomers (Fig. 1). For example, the reversed orders of mutagenicities observed in bacterial and in mammalian cells $(1,2,8)$ may be due to differences in the recognition of these two types of lesions by repair enzymes and/or the cellular replication machinery. We have demonstrated this year that the rates of digestion of adducts by a simple exonuclease, in which the DNA strands are digested to the monomeric 
A
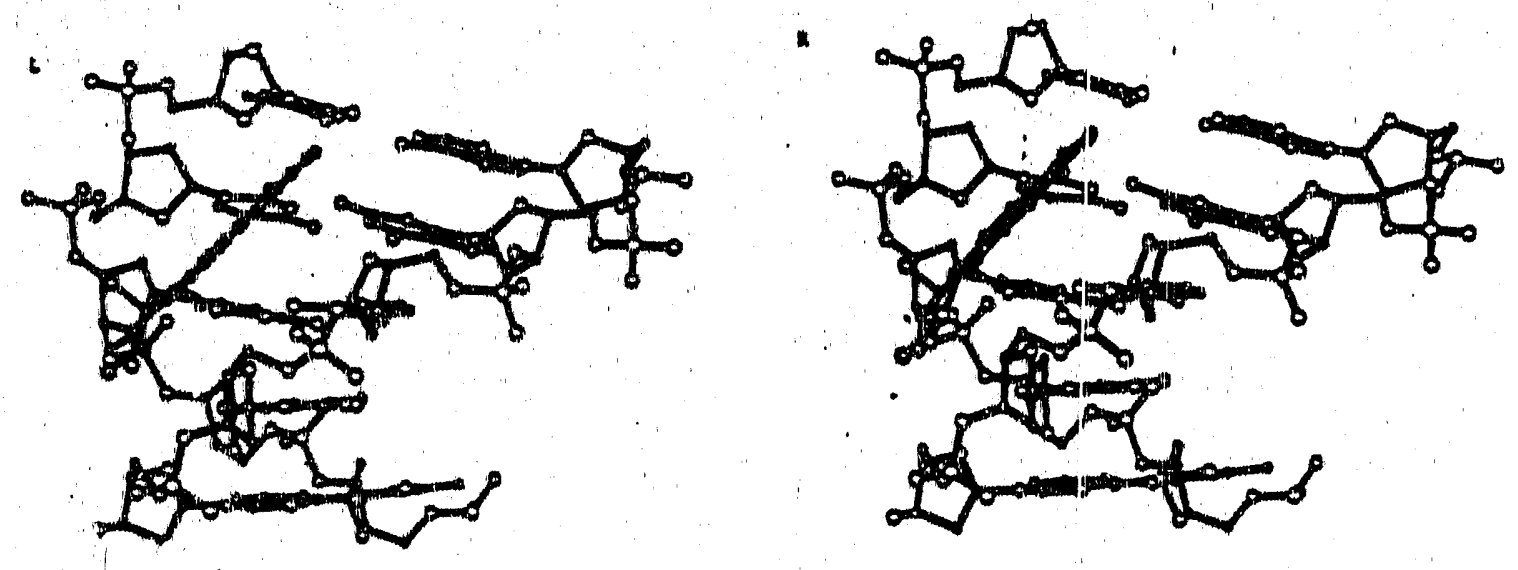

(-)-trans-antl-BPDE-N2-dG

B
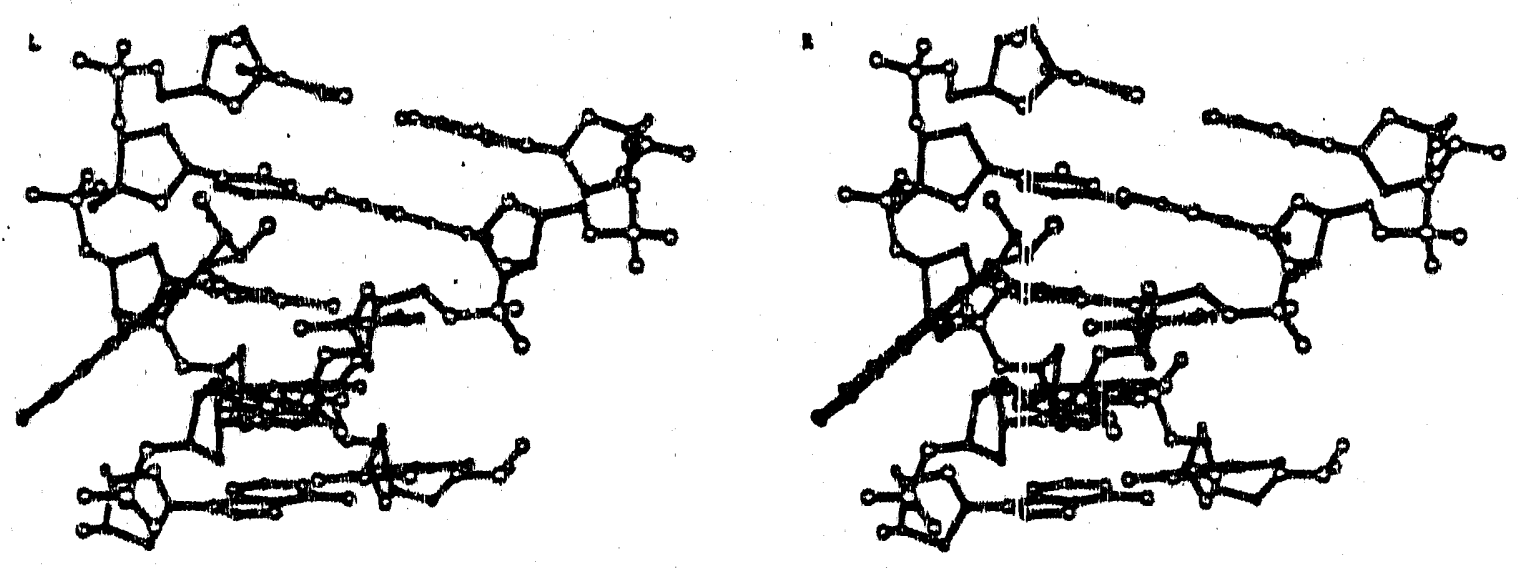

$(+)$-trans-anti-BPDE-N2-dG

Fig. 3 
nucleotide levels; are indeed different for DNA adducts derived from the binding of $(+)$-antiBPDE and (-)-anti-BPDE to short DNA fragments.

The determinations of the BPDE-DNA adduct structures are the first of their kind. The possibility of investigating the interactions of these stereospecific and site-specific PNADNA adducts with selected enzyme systems is a most exciting development.

\section{B. INTERACTIONS OF ENZYMES WITH STERICALLY DIFFERENT}

\section{BENZO/a]PYRENE DIOL EPOXIDE-OLIGONUCLEOTIDE ADDUCTS.}

The biological endpoints of PNA-DNA lesions include cell death, mutations, and carcinogenesis. The latter is a complex multi-step process which is believed to arise from a series of mutations. The biological activities of bulky polycyclic aromatic hydrocarbonDNA adducts in general are expressed via the interactions of these lesions with repair enzymes, with the replicative enzyme systems, or result from protein-DNA interactions which are altered by the lesions. In order to gain an understanding of biological activity-structure relationships, it is necessary to characterize first the structures of the PNA-DNA lesions, and subsequently to investigate how the normal functioning of relevant replication and other enzymes is affected by these adducts. Within the last year we have launched new programs to investigate the effects of BPDE-DNA lesions on the functioning of certain important enzymes. Three different types of systems have been studied up till now, or are presently being investigated. These systems include:

(1) Kinetics of enzyme digestion of BPDE-modified oligonucleotides.

(2) Ligation of BPDE-modified oligonucleotides by ligases. 
(3) In vitro polymerization experiments in which a BPDE-modified oligonucleotide template is replicated using standard polymerases.

We have made sufficient progress on parts (1) and (2) to include a summary in this report. Experiments on in vitro polymerase reactions (part 3) are presently in progress.

\section{Enzyme digestion kinetics of stereochemically different BPDE-DNA Adducts.}

It has been reported that the digestion of certain bulky DNA adducts by exonucleases such as snake venom phosphodiesterase I (SVDP) and spleen phosphodiesterase II (SPD) is significantly slowed by the presence of the lesions $(9,10)$. We have observed anaiogous effects with the trans-adducts derived from the binding of (+)-anti-BPDE and (-)-anti-BPDE with oligonucleotides. Since the conformations of these adducts have been elucidated by NMR methods (see above), these differences in enzyme kinetics can be related to their structures.

The exonuclease SVDP digests single-stranded DNA to nucleotide monomer units starting from the 3'-end of the strand, progressing towards the 5'-end. The enzyme SPD fulfills a similar function, but digestion progresses from the opposite end of the DNA strands, that is from the 5 '-end towards the 3 '-end. The actions of these two exonucleases can be summarized as follows:

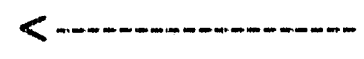

SVDP:

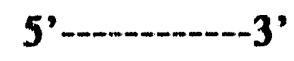




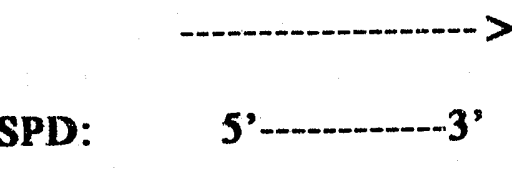

where the 5'-----3' designation specifies the DNA strand polarity, while the arrows denote the directions of digestion of the two enzymes.

Experimental protocols. In our experiments, the enzymes are allowed to act on unmodified or BPDE-modified oligonucleotides 16 bases long for varying periods of time (30 $\mathrm{s}, 2 \mathrm{~min}, 30 \mathrm{~min}, 60 \mathrm{~min}$ and $90 \mathrm{~min}$ ). Briefly, the protocol involves solutions containing 1 $\mu \mathrm{g}$ of DNA adduct in $0.11 \mathrm{M}$ Tris buffer, $\mathrm{pH} 8.9,15 \mathrm{mM} \mathrm{MgCl}{ }_{2}$ containing 0.0002 units phosphodiesterase I at room temperature. The digestion is terminated by adding EDTA to a final concentration of $10 \mathrm{mM}$. By stopping the reaction at different time intervals, a distribution of partially digested oligonucleotides of different lengths can be obtained. The reaction mixture is then subjected to $20 \%$ polyacrylamide gel electrophoresis in order to visualize the relative concentrations of the oligonucleotide fragments of different masses by standard ${ }^{32} \mathrm{P}$-end labeling and autoradiography. This approach is schematically depicted in Fig. 4.

\section{Results obrained with SVDP ( $\left(3^{\prime}-->5^{\prime}\right.$ 'digestion).}

Typical data obtained with modified and unmodified 16-mers

(III) d(CTCACATG ${ }^{\text {QPDE TACACTCT) }}$

(IV) d(CTCACATGTACACTCT)

are shown in Fig. 5. The lanes on the extreme left and right hand sides depict the results of digestion of the unmodified 16-mer for only 30 seconds. There is no band at the very top 
EFFECTS OF BPDE-N2-dG LESIONS IN OLIGOS ON ENZYME DIGESTION BY SNAKE VENOM PHOSPHODIESTERASE,

DIRECTION OF DIGESTION BY SVPD:

5'-d(CCATCG*CTACC) 11-MER

5'-d(CCATCG*CTAC) 10-MER

5'-d(CCATCG*CTA) 9-MER

$5^{\prime}-d\left(C^{\prime} C^{2}\right.$ CG $\left.^{*} C T\right)$

8-MER

$5^{\prime}-d\left(\right.$ CCATCG $\left.^{*} \mathrm{C}\right)$

7-MER

$5^{\prime}-d\left(C^{\prime} C A T C G^{*}\right)$

6-MER

etc.

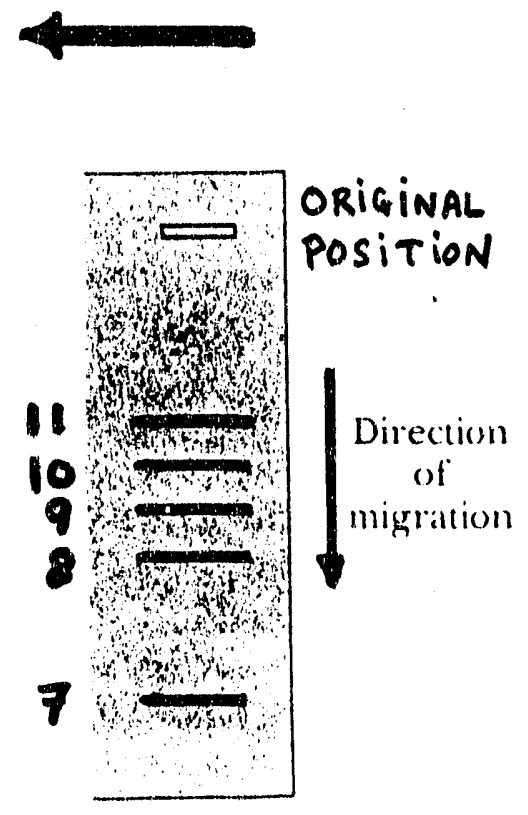

GEL. ELECTROPHORESIS

Fig. 4 


\section{SNAKE VENOM PHOSPHODIESTERASE DIGESTION OF d(CTCACATG ${ }^{\text {BPDE }}$ TACACTCT)}

(t)-anti-BPDE

(*)-anti-BPDE

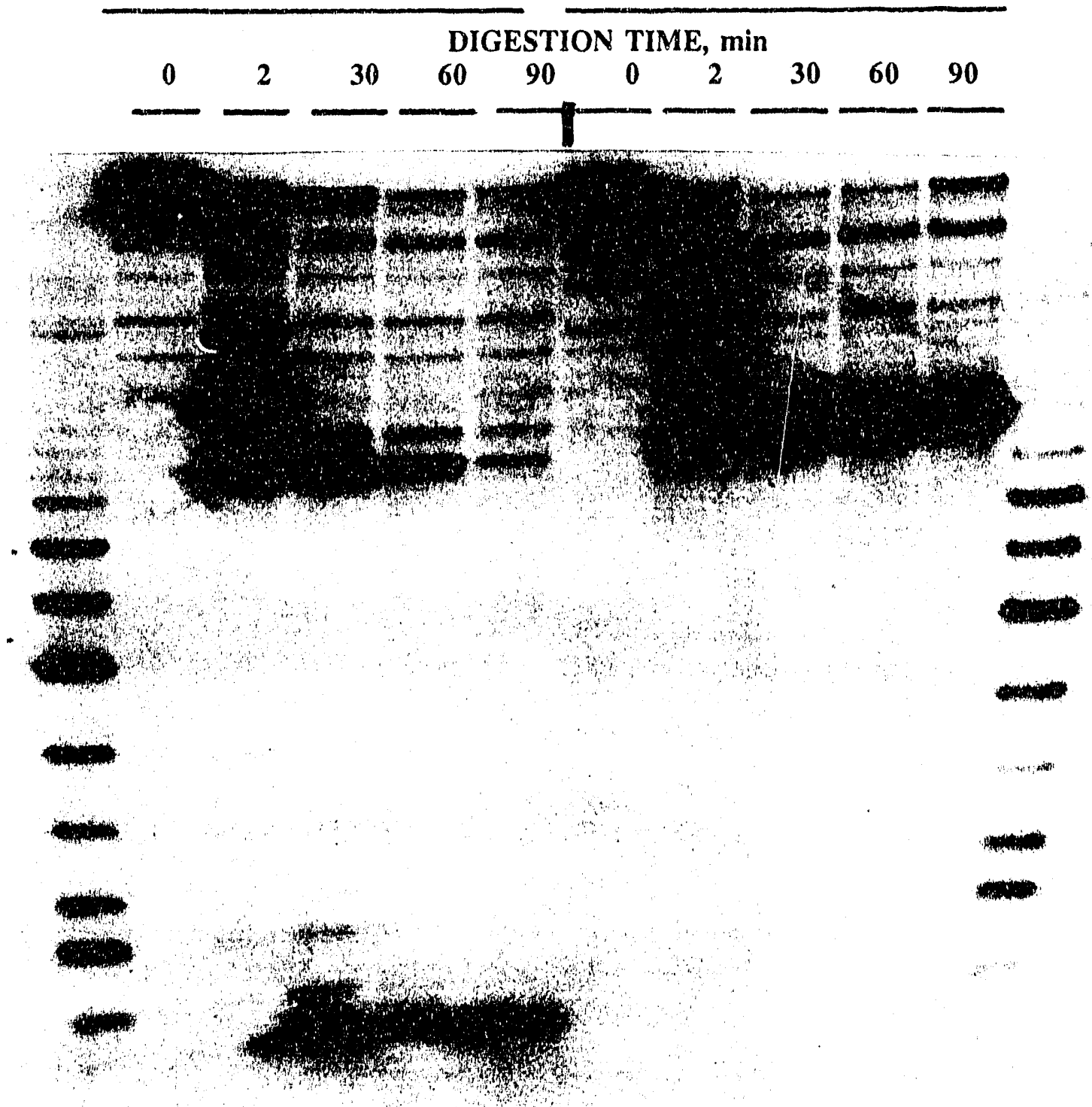

Fig. 5 
which indicates that all of the unmodified 16-mer had been digested, at least partially; the bands occurring in these lanes are due to shorter fragments as indicated schematically in Fig.

4.

The lanes marked "0" for the $(+)$-trans-BPDE and (-)-trans-BPDE 16-mer adducts are the undigested control samples, and only one band is observed, as expected. After 2 min of digestion, there is still a considerable amount of undigested adducted 16-mers left, as indicated by the dark bands at the top of the gel and at the same level as the band in the "0" lane, corresponding to the undigeste 16-mer. It is therefore evident, that the progress of SVDP is significantly slowed in the case of both (+)- and (-)-trans-BPDE adducted 16-mers. In fact, in both cases dark bands arise at positions corresponding to the 8-mer fragment:

\section{d(CTCACATG $\left.{ }^{\mathrm{APDE}}\right)$}

suggesting that the bulky BPDE moiety represents at least a par ial block with respect to digestion by SVDP. However, there is a significant difference between the $(+)$-trans- and the (-)-trans-adducts: after 90 min of digestion, the digestion of the (+)-adduct is almost complete (only a few faint bands are observed in the upper portions of the 90 min lane in the case of the $(+)$-anti-16-mer adduct (Fig. 5). In the case of the (-)-adduct, the band due to the unmodified 8-mer is quite prominent even after 90 min of digestion.

From the experiment depicted in Fig. 5, we conclude that the (-)-anti-BPDE-DNA adduct is much more resistant to digestion by the exonuclease snake venom phosphodiesterase I than the corresponding (+)-anti-BPDE-16-mer adduct.

\section{Digestion with the $5^{\prime}--->3^{\prime}$ exonuclease SPD}

The above experiments performed with the 3 '----> 5' exonuclease SVPD were 
repeated with the 5'---->3' exonuclease spleen venom phosphodiesterase II (results not shown). Exactly the opposite pattern was observed than with SVPD I: the (+)-anti-BPDE 16-mer was more resistant to digestion than the (-)-anti-BPDE 16-meric oligonucleotide.

\section{Conclusions}

These fascinating results can be understood if it is assumed that the blockage of the two different enzymes are dependent on the stereochemistry of the BPDE- $\mathrm{N}^{2}-\mathrm{dG}$ lesions in the 16-mer. If we assume that the (+)-BPDE enantiomer pyrenyl residue is pointing towards the 5'-end, while in the case of the (-)-BPDE adduct it points towards the 3'-end (as found by NMR for the mini-helices), these results may be understood as follows:

(i) the progress of the SVPD enzyme is impeded by the (-)-BPDE which meets it "head-on" as the enzyme progresses from the 3' towards the 5'-direction.

(ii) the progress of the same enzyme is less impeded when the pyrene ring system points in the same direction $\left(3^{\prime}--->5^{\prime}\right)$ as the progression of the enzyme, which is also from 3' to 5'.

From these assumptions, it follows that SVDP enzyme digestion should be faster in the case of the (+)-BPDE than in the case of the (-)-BPDE oligonucleotide adduct. This scheme is schematically summarized in Fig. 6.

This scheme predicts that SPD, which digests in the opposite direction than SVDP, should digest the (-)-BPDE adducts faster than the (+)-BPDE adducts. This is indeed observed experimentally, thus supporting the scheme of enzyme activities summarized for SVDP and the two different adducts studied in Fig. 6.

These startling observations, though obtained with simple exonucleases, suggests why 


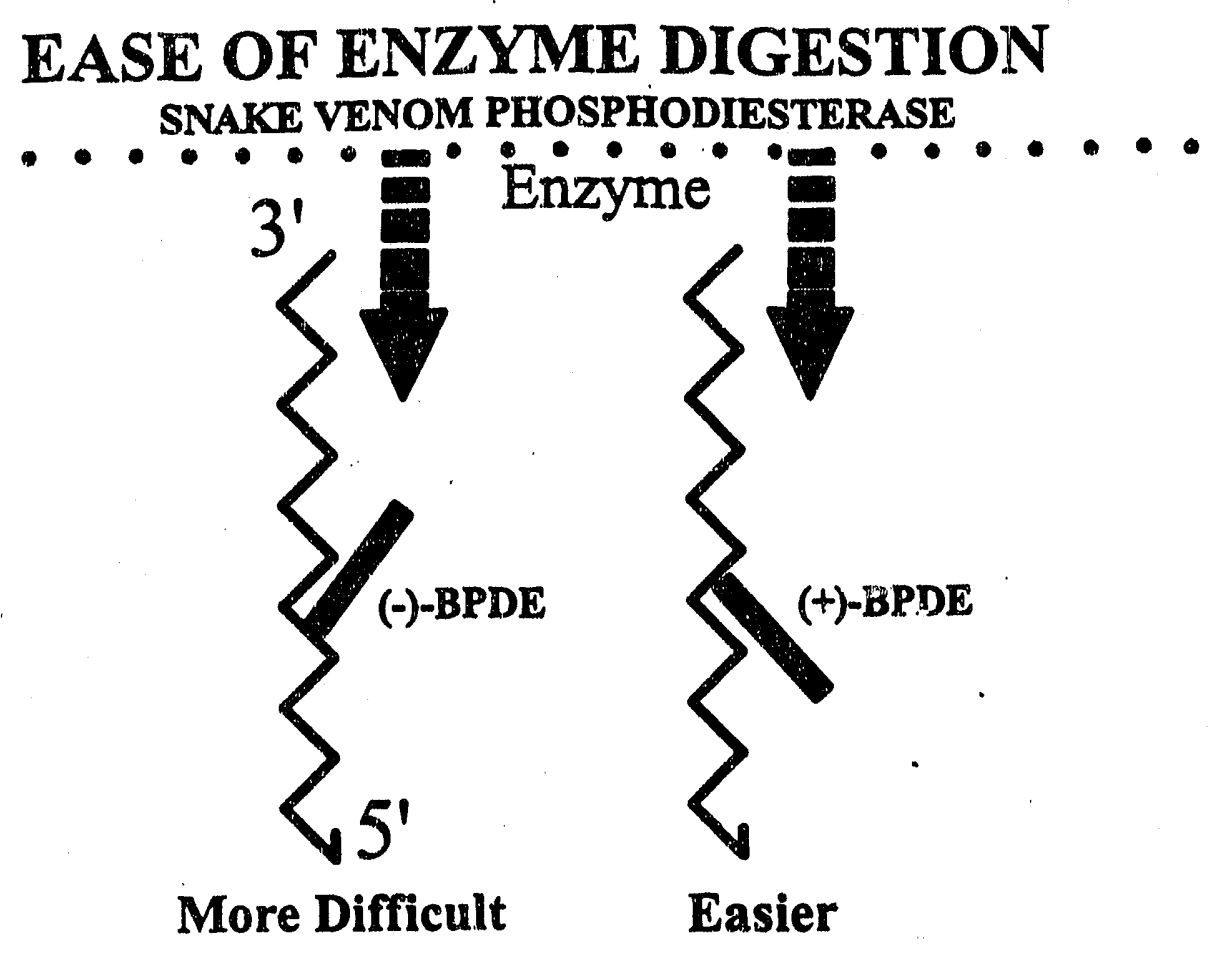

Fig. 6

LINEAR MULTIMERS

CIRCULAR MULTIMERS
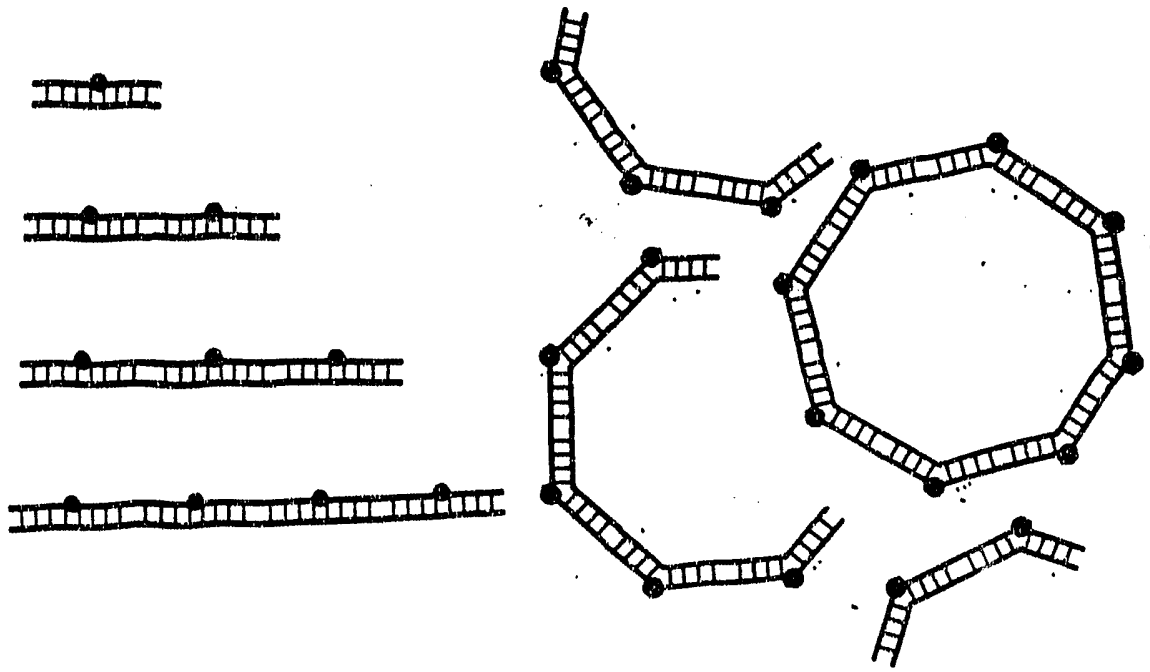

Fig. 7 
the biological activities of the trans-adducts derived from the enantiomers (+)-anti-BPDE and (-)-anti-BPDE may be different from one another: the bulky pyrenyl residues are oriented in different directions relative to the DNA 5'---.-->3' strand polarity (as observed by NMR techniques), thus affecting the functioning of direction-sensitive enzymes to different extents.

The replicative enzymes, the polymerases, operate along the 5 '-.-- $>3$ ' direction, with exonuclease editing activity operating in the $3{ }^{\prime}--->5^{\prime}$ direction. Based on our findings, it is tempting to speculate that analogous directional effects are of critical importance in the replication past a bulky PNA-DNA lesion in vivo. Since polymerase complexes are different in mammalian and in bacterial cell systems, it is possible that the differences in the mutagenicities of (+)-anti-BPDE and (-)-anti-BPDE may arise from the type of orientational effects observed by us with simple exonucleases.

\section{Unusual hinged bends at BPDE-DNA lesion sites revealed by enzymatic.}

\section{lization of modified oligonucleotides.}

The distortion of the local DNA structure by the presence of a bulky carcinogen such as BPDE is likely to have a profound influence on the interactions of this modified DNA segment with enzymes and proteins which are important in gene regulation. In fact, certain proteins, upon binding to DNA, are known to cause bends in the double helix which activates the genes. We have previously found, using flow linear dichroism techniques, that the binding of (+)-anti-BPDE to native DNA causes an increased flexibility of the DNA backbone, while the effect of (-)-anti-BPDE on this hydrodynamic property of DNA is much less pronounced (11, see also ref. 12). The severity of these effects seem to depend not only 
on the BPDE. stereoisomer, but also on the base sequence in which the BPDE lesion is located (13), In the latter case, our experimental evidence suggests that (+)-anti-BPDE causes an enhancement of the local flexibility at the site of the lesion rather than a stiff directed bend; such regions of local flexibilities induced by the covalent binding of bulky carcinogens are called "flexible hinge joints" (14).

Because of the potential importance of bends or hinge joints in gene regulation, and our success in synthesizing stereochemically defined BPDE-oligonucleotide complexes, we decided to examine the occurrence of such bends or hinge joints in detail. The occurrence of bends or hinge joints in oligonucleotide segments can be revealed by ligating the monomeric oligonucleotides to form multimers of various higher molecular weights. The literature on this subject is copious and we refer here only to the papers by Leng and coworkers which are most relevant to the effects produced by bulky carcinogens $(14,15)$.

Experimental protocols. In this method, about $2 \mu \mathrm{g}$ of BPDE-modified or unmodified oligonucleotides are labeled with ${ }^{32} \mathrm{P}$-ATP at the 5 '-end using standard T4 kinase labeling kits. These single strands are then complexed with their complementary strands to form mini-helices. These small duplexes (typically 16-23 base pairs long) and are purified by gel electrophoresis using $20 \%$ polyacrylamide gels. The purified duplexes are then dissolved in TE buffer solution ( $\mathrm{pH} \mathrm{7.0)}$ and heated to $70^{\circ} \mathrm{C}$; upon slow cooling to room temperature, double helices are formed. The mini-helices are then self-ligated to produce multimers using the enzyme ligase (10 units) in a commercially available ligation buffer at $10{ }^{\circ} \mathrm{C}$ for two days. The molecular weights of the multimers are integral multiples of the starting min-helices. For example, if we start with a 16-mer, a mixture of multimers is produced which are 32, 
$48,64,82 \ldots \ldots .$. etc. base pairs long. The presence of these DNA minihelices can be revealed by gel electrophoresis on non-denaturing gels (electrophoresis using $10 \%$ polyacrylamide gels for 12 hours at $4^{\circ} \mathrm{C}$ and $5 \mathrm{~V} / \mathrm{cm}$ ).

The mobility of the different multimers on electrophoretic gels is markedly diminished if there are bends or hinge joints at the site of binding of the carcinogen (15). This retardation arises because the electrophoretic mobility of DNA segments depends not only on their molar masses and electrical charge, but also on their end-to-end distance. Bent segments, or flexible segments have, on the average, a smaller end-to-end distance, and thus migrate slower than fragments of equivalent mass and electrical charge. This retardation is capable of revealing the existence of bends or flexible hinge joints. If bends or hinge joints are present, successive ligation of multimers can even produce covalently closed circles. The principles involved behind this ligation method, is summarized schematically in Fig. 7.

In our experiments, the modified and unmodified 16-mers (III) and (IV) (see above) were self-ligated, and the multimer products were analyzed by gel electrophoresis as described above. Four types of modified 16-mers were employed in these studies and included (+)-trans-BPDE-dG, (-)-trans-BPDE-dG, (+)-cis-BPDE-dG, and (-)-cis-BPDE-dG adducts. A photograph of a typical electrophoresis result is shown in Fig. 8; results are shown only for (from left to right): unmodified DNA, (+)-trans-BPDE-dG-oligonucleotides, and (-)-trans-BPDE-dG-oligonucleotides. The results obtained with (+)-cis, and (-)-cisBPDE-dG oligonucleotides were almost the same as those for the (-)-irans-BPDE-dG adducts, and are therefore not shown. Since the original photographs may not reproduce well xerographically, the positions of the bands are also reproduced schematically in Fig. 8. 


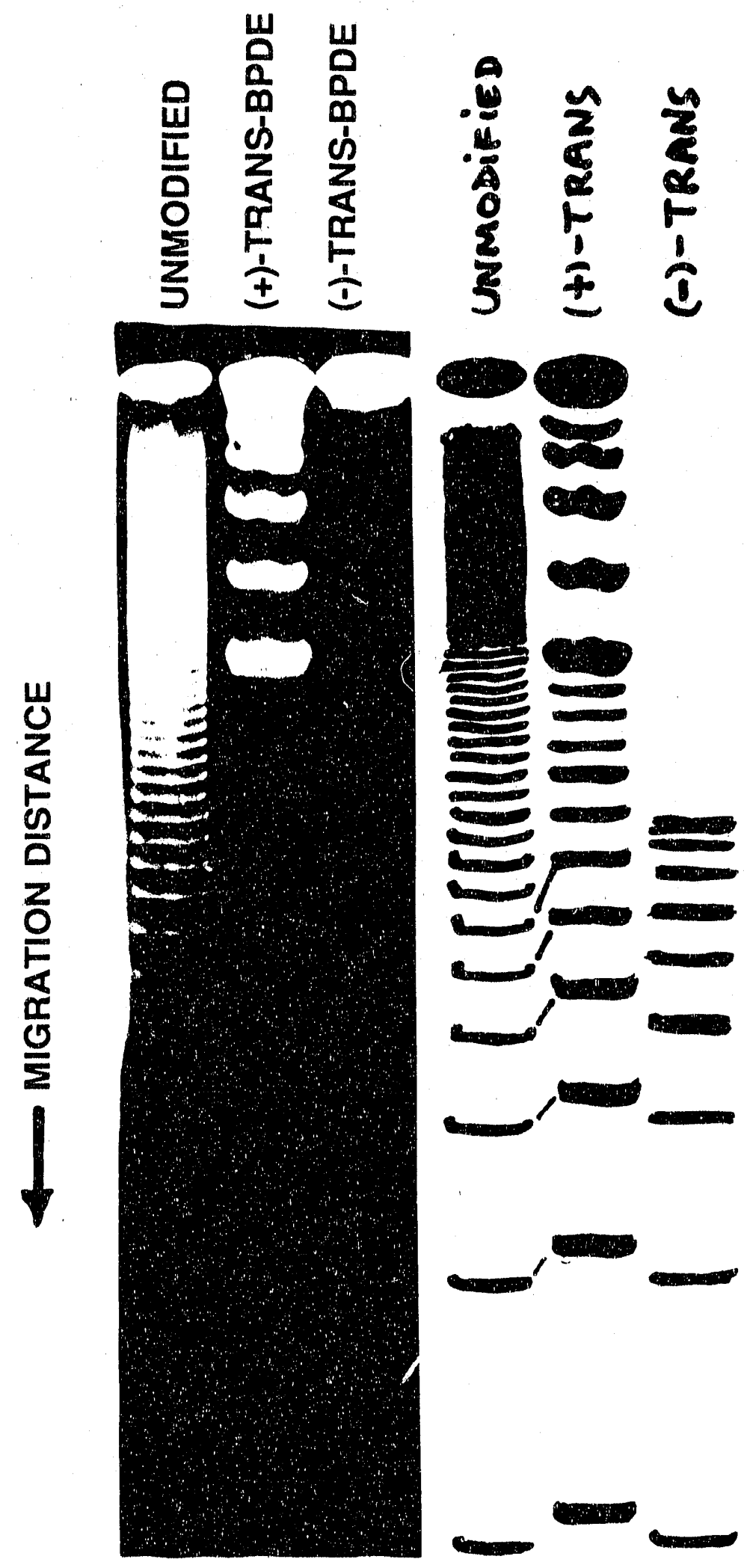

Fig. 8 
The key observations can be summarized as follows:

(1) The unmodified ligated 16-mers form a regular ladder; the lengths in terms of the numbers of base pairs are indicated next to each of the bands in the schematic portion of the diagram in Fig. 8. In the case of the (+)-trans oligonucleotides, each corresponding band (indicated by thin lines) migrates with a slower mobility. In the case of the (-)-trans-BPDE adducted oligomers, a retardation is also observed, but it is much less pronounced than in the case of the (+)-BPDE-dG adducted oligomers.

(2) Most interestingly, in the case of the (+)-trans-BPDE adducts, a pronounced series of higher molecular weight bands are observed, which are not present either in the lane corresponding to the unmodified or the (-)-trans-BPDE adducts. These bands are ascribed to the formation of closed circles, as shown in the schematic diagrams of Fig. $7 . \quad$ Neither the (-)-trans-, nor the (+)- cis and (-)-cis-BPDE-dG oligomers exhibit circular DNA formation!

(3) Out of the four stereochemically different BPDE- $\mathrm{N}^{2}-\mathrm{dG}$ adducts derived from the two enantiomers (+)- and (-)-anti-BPDE, only the trans-(+)-BPDE adduct shows an unusual bend or hinge joint, which results in the formation of closed circles as depicted in Fig. 7.

(4) The unusual characteristics of the trans-(+)-BPDE-dG lesion in the different multimers is best expressed by the ratio $\mathbf{R}$ :

$$
\mathbf{R}=\text { (apparent mass of modified } \mathbf{n}-\mathrm{mer}) /(\text { mass of unmodified } \mathbf{n} \text {-mer) }
$$

where the apparent masses are deduced from the positions of the bands due to each n-mer ( $n$ $=1,2,3,4 \ldots$ ) on the electrophoretic gel (Fig. 8). The ratio $\mathrm{R}$ is plotted as a function of the number of base pairs in each oligonucleotide (multiples of 16) in Fig. 9. The $(+)$-trans 


\section{ielative Retardation ( $R$ ) of Multimer BPDE- $N^{2}$-dG Adducts 5'-d(CTCACATG BPDETACACTCT)-3'}

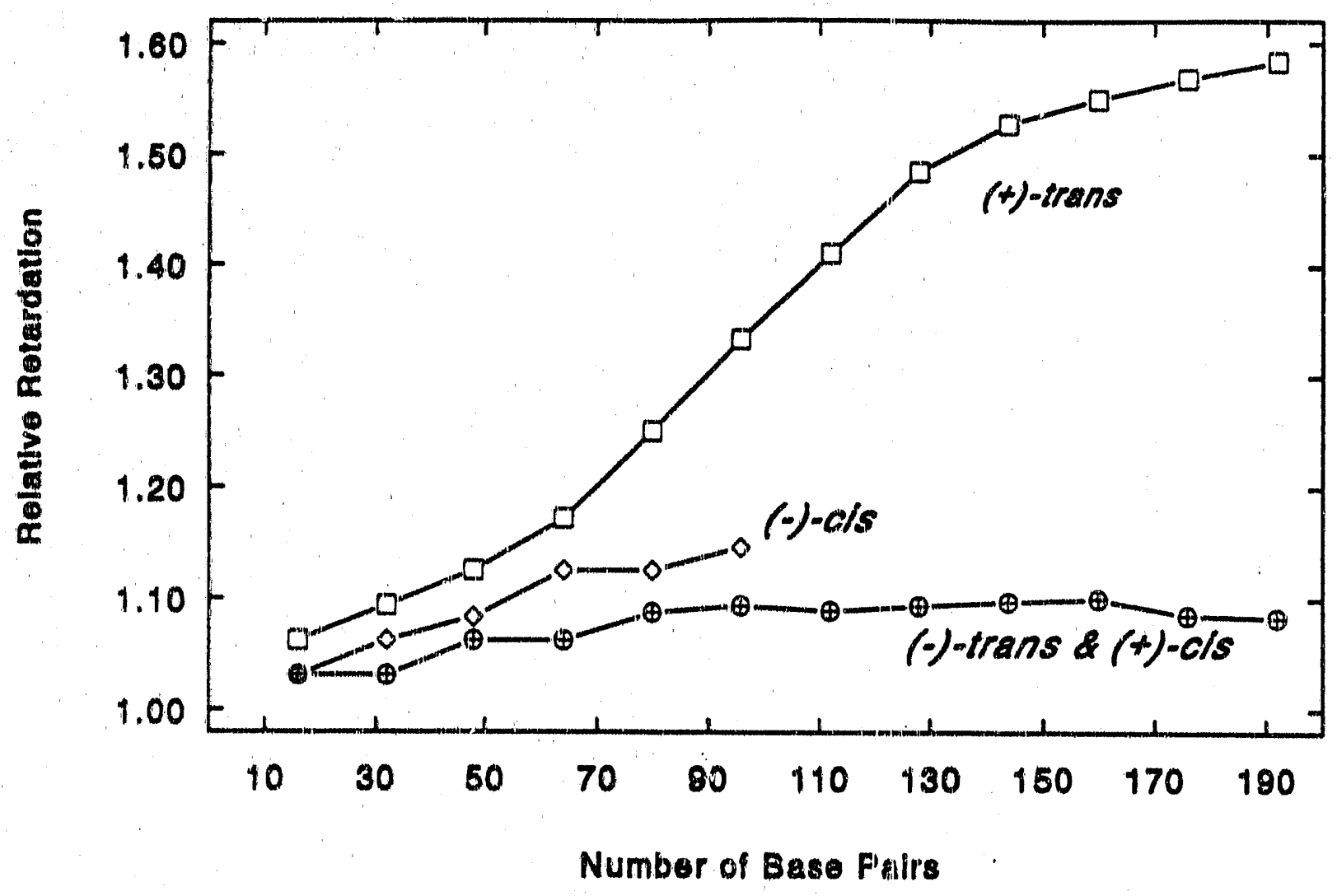

Fig. 9 
clearly shows the highest apparent masses for each n-mer, thus confirming that the end-to-end distance is shorter in that adduct than in the unmodified, or in the (-)-trans, and the (+)- and (-)-cis oligomers. This is due to the existence of a directed stiff bend or flexible hinge joint at the site of the lesion in the (+)-trans-BPDE-dG adducted oligomers.

(5) The issue of distinguishing between a stiff directed bend and a flexible hinge joint in the (t)-trans-BPDE-dG oligomer adducts can be settled by repeating the experiments, the results of which are shown in Figs. $7 \& 8$, with oligomers containing 2 full turns (22-23 base pairs long). In the case of a flexible hinge joint, $R$ should vary in the same way for the 23 mer ( 2 helix turns) as for the ligated 16-mer (1.5 turns) (14-16). This is indeed found to be the case (data not shown), and we conclude that the trans- $(+)-B P D E-d G$ lesions are charocterized by a flexible hinge joint at the site of the lesion, in contrast to the other stereochemically different BPDE-dG adducts in which this effect is not pronounced.

\section{Conclusions}

The (+)-anti-BPDE enantiomer is the most tumorigenic stereoisomer among the four stereoisomers of BPDE. While the characteristics of the two syn - stereoisomers have not yet been investigated, it is evident that the trans- $\mathrm{N}^{2}-\mathrm{dG}$ lesions derived from $(+)$-anti-BPDE are quite different from those derived from the (-)-anti-BPDE isomer. This characteristic may account for the striking differences in the tumorigenic activities of the $(+)-$ and $(-)-$ enantiomers of anti-BPDE. We hope to continue to develop the tools which are necessary for iurther unraveling the fascinating relationships between the biological activities and the structural characteristics of DNA lesions derived from the binding of these reactive PNA metabolites to DNA. 


\section{REFERENCES}

1. Conney, A.H. (1982) Cancer Res. 42, 4875-4917.

2. Stevens, C.W., N. Bouck, Burgess, J.A., and Fahl, W.E. (1985) Mutat. Res. 152, 5-14.

3. Cosman, M., Ibanez, V., Geacintov, N.E. and Harvey, R.G. (1990) Carcinogenesis $11,1667-1672$.

4. Geacintov, N.E., Cosman, M., Mao, B., Alfano, A., Ibanez, V. and Harvey, R.G. (1991) Carcinogenesis 12, 2099-2108.

5. Cheng, S.C., Hilton, B.D., Roman, J.M. and Dipple, A. (1989) Chem. Res. Toxicol. 2, 334-340.

6. Cosman, M., de los Santos, C., Fiala, R., Hingerty, B.E., Ibanez, V., Margulis, L.A., Live, D., Geacintov, N.E., Broyde, S., and Patel, D.J. (1992) Proc. Natl. Acad. Sci. (USA) 89, 1914-1918.

7. de los Santos, Cosman, M., Hingerty, B.E., Ibanez, V., Margulis, L.A., Geacintov, N.E., Broyde, S., and Patel, D.J. (1992) Biochemistry 31, 5245-5252.

8. Brookes, P. and Osborne, M.R. (1982) Carcinogenesis 3, 1223 - 1226.

9. Dipple, A. and Pigott, M.A. (1987) Carcinogesasis 8, 491-493.

10.Cheh, A.M., Yagi, H. and Jerina, D.M. (1990). Chem. Res. Toxicol. 3, 545-550.

11. Roche, C.J., Geacintov, N.E., Ibanez, V. and Harvey, R.G. (1989) Biophys. Chem. 33, $277-288$.

12. Eriksson, M., Nordén, B., Jernström, B. and Gräslund, A. (1988) Biochemistry 27, 1213-1221. 
13. Roche, C.J., Jeffrey, A.M., Mao, B., Alfano, A., Kim, S.K., Ibanez, V. and Geacintov, N.E. (1991) Chem. Res. Toxicol. 4, 311-317.

14. Leng, M. (1990) Biophys. Chem. 35, 155-163.

15. Schwartz, A., Marrot, L. and Leng, M. (1989) . J. Mol. Biol. 207, 445-450.

16. Bellon, S.F., Coleman, J.H., and Lippard, S.J. (1991) Biochemistry 30, 8026-8035. 
PART II

TIME-RESOLVED PICOSECOND LASER PULSE SPECTROSCOPY FOR PROBING ELECTRONICALLY EXCITED STATE INTERMEDIATES IN POLYNUCLEAR AROMATIC PARTICULATES. 
Photoemission of electrons from a condensed phase can occur even when the absorbed photon energy is lower than the ionization potential of that phase. In such cases, the mechanisms of photoionization may involve interactions between excired states, or excited state-photon absorption phenomena, giving rise to superlinear intensity dependences of photoelectron yields. In general, it is difficult to identify the excited states which serve as intermediates in second or higher order photoionization processes, particularly if their lifetimes are in the subnanosecond range.

At present, the major technique for determining the lifetime of transient vibronic states is by measuring the rate of decay of the fluorescence from such states following their excitation by suitably short light pulses. However, not all molecules fluorensce, so it is useful to have available a method that does not depend on fluorescence. Photoemission fulfills that requirement.

We have developed a new general method for measuring the lifetimes of excited states in the condensed phase using crystalline tetracene as the model system. This method is based on a multi-step photoemission process in which the rate of decay of an excited state generated by a prompt pulse is measured by the use of a delayed probe pulse. We show that the most likely intermediate in tetracene is a charge-transfer state with an energy of $2.9 \mathrm{eV}$ and a lifetime of $\sim 20$ ps (and probably less than $100 \mathrm{ps)}$ in the surface region ( $15 \mathrm{~A})$ of the crystal. Photoemission occurs via a single photon ionization of this CT state.

Photoemission in organic molecular crystals is competitive in rate with that of decay from higher excited states to lower excited states within a molecular manifold. These rates can be in the sub-picosecond range [1]. Tetracene is of interest because it has been well-studied, 
can be obtained in pure form, has a low fluorescence efficiency [2], and has a charge-transfer (CT) state [3] whose lifetime has never been measured. In this paper, we show that using a multi-step process for producing photoemission, it is possible to measure lifetimes.

The experimental technique involves the use of our modified Millikan chamber [4], in which a small crystal ( $\sim 50 \mu$ diameter) of tetracene is suspended in nitrogen at 1 atmosphere pressure. The suspended crystal is negatively charged initially, and the loss of that charge as a result of photoemission is the measured quantity. By measuring the rate of the loss of charge, the ernission photocurrent is deduced. We measure the loss of charge by recording the field strength that is required to balance the crystallite against the force of gravity [4]. It is not necessary to have any sophisticated sub-picosecond current measuring circuitry to determine lifetimes.

In a typical experiment, a suspended crystallite is excited by a primary beam consisting of the $355 \mathrm{~nm}$ harmonic of a YAG laser (35ps FWHM as specified by the manufacturer) and subsequently, by a suitably delayed probe pulse derived from the same beam. In the present case, the wavelengths of the primary and probe beams were the same, but it is possible to choose any other wavelength for the probe beam. The rate of decay of the population of excited states created by the primary beam is probed by the delayed beam, which interacts with the surviving excited states to produce photoemission.

In the present case, the primary beam itself produces photoemission by a multi-step process so it is necessary to sort out the contributions from each beam.

The mechanism of the photoemission process is deduced by measuring the maximum kinetic energy $\left(\mathrm{KE}_{\mathrm{max}}\right)$ of the escaping electrons, and by measuring the light intensity (I) 
dependence of the photoemission current (Y). As an example, if the photoemission process depended on the cube of the light intensity, i.e. $Y \propto I^{3}$, then at coincidence of the primary and probe beams of equal intensity, the light intensity would be doubled, and the yield would be four times greater than that produced by the sum of the yields when the primary and secondary beams do not produce overlapping excited state populations. In general, if beams of equal intensity and energy are used, then the ratio $Y_{\max } / Y_{\min }=2^{n-1}$, where $Y_{\max }, \quad Y_{\min }$, and $n$ are respectively, the maximum and minimum photoemission yields, and the calculated intensity dependence of the photoemission. This relationship holds only when each beam produces photoemission.

The ionization energy of crystalline tetracene is $5.3 \mathrm{eV}$ [5], the singlet and triplet states lie at 2.3 and $1.65 \mathrm{eV}$ respectively [6], the vertical band gap has been put at $3.5 \mathrm{eV}$ [7], and a CT state at $2.9 \mathrm{eV}$ has been identified [8]. The singlet state lifetime is about $200 \mathrm{ps}$ [9]. In the present experiment, the maximum kinetic energy of the emitted electrons was found to be $1.1 \mathrm{eV}$, implying that in the multi-step photoemission process, the combined energy (to be referred to as the equivalent single photon energy, $E_{q}$ ) of the interacting states was $6.4 \mathrm{eV}$. Thus, if a photon at $3.5 \mathrm{eV}$ were to photoionize a free electron in the conduction band at $3.5 \mathrm{eV}$, the value of $\mathrm{E}_{\mathrm{q}}$ would be $7.0 \mathrm{eV}$; since the measured $\mathrm{E}_{\mathrm{q}}$ was $6.4 \mathrm{eV}$, the photon-free electron mechanism is eliminated. The light intensity dependence of the photoemission was greater than quadratic; it was 2.4. This eliminates the direct two-photon ionization mechanism, for which $\mathrm{Y} \propto \mathrm{I}^{2}$ and $\mathrm{E}_{\text {eq }}$ $=7.0 \mathrm{eV}$.

The photoemission yield as a function of the delay time between the primary and probe pulse is shown in Fig. 1. The point of coincidence is determined by using photoemission from 
the particle as the indicator; when maximum photoemission is measured, coincidence is achieved. The maximum photoemission yield can be measured in advance by sending in an undivided (full intensity) beam. The yield at this intensity is assumed to be the same (factoring in reflection losses) as that obtained when the primary and probe beams are coincident.

The intensities of the primary and probe pulses were approximately equal. For the $35 \mathrm{ps}$ pulse, the light intensity was $10^{16} \mathrm{~cm}^{-2}$ pulse $\mathrm{s}^{-1}$. Using the absorption coefficient at $355 \mathrm{~nm}$ of about $10^{3} \mathrm{~cm}^{-1}[10]$, the initial singlet exciton population is about $10^{19} \mathrm{~cm}^{-3}$ at maximum light intensity in the pulse.

The light intensity dependence of the photoemission process was always greater than 2 and most often was 2.3 \pm 0.1 . Possible mechanisms for photoemission would include photon-photon, photon- singlet exciton, photon- $\mathrm{CT}_{d}\left(\mathrm{CT}_{\mathrm{d}}\right.$ is a $\mathrm{CT}$ state generated directly by a photon), singlet-singlet, photon-free or trapped electron, $\mathrm{CT}_{d}+\mathrm{CT}_{\mathrm{d}}$, photon-CT $\left(\mathrm{CT}_{\mathrm{i}}\right.$ is a $\mathrm{CT}$ state generated indirectly by singlet-singlet annihilation), $\mathrm{CT}_{i}+\mathrm{CT}_{i}$, electron $+\mathrm{CT}_{\mathrm{i}}$, and singlet + singlet + singlet. Of the above, only the (photon $\left.+\mathrm{CT}_{\mathrm{i}}\right)$ and the $\left(\right.$ electron $\left.+\mathrm{CT}_{\mathrm{i}}\right)$ could satisfy the observed light intensity dependence of $\mathrm{X} \propto \mathrm{I}^{2.4}$ and the measured value of $\mathrm{E}_{\mathrm{q}}=6.4$ $\mathrm{eV}$. The photon energy was $3.5 \mathrm{eV}$ and the $\mathrm{CT}$ energy is $2.9 \mathrm{eV}$, adding up to $6.4 \mathrm{eV}$. The free electron energy is coincidentally also about $3.5 \mathrm{eV}$ so the (e - CT) mechanism would satisfy the energy requirement and it also happens to satisfy the light intensity dependence requirement. For reasons to be mentioned later, the (e - CT) mechanism is not favored, so in the analysis to follow, the photon- $\mathrm{CT}_{\mathrm{i}}$ mechanism will be used. The relevant processes are the following: 
1) $\quad h_{-}+S_{0} \rightarrow S_{1} ; \quad$ excitation to the first singlet state.

2) $S_{1}+S_{1} \rightarrow S^{*} ; \quad$ singlet-singlet fusion with rate constant $\gamma_{s s}$

3) $\quad S^{*} \rightarrow \mathrm{CT}_{i} ; \quad$ CT state is formed with efficiency $\eta$.

4) $h_{-}+\mathrm{CT}_{1}->\mathrm{h}^{+}+\mathrm{e}^{-*}-\rightarrow$; $\mathrm{CT}_{1}$ is photoionized with a cross- section $\sigma$ producing the photoemitted electron $e^{* *}$.

5) $\quad S_{1} \rightarrow S_{0}$

unimolecular singlet decay with rate constant $\mathbf{k}_{\mathbf{s}}$.

6) $\quad \mathrm{CT}_{\mathrm{i}} \rightarrow \mathrm{S}_{1}$; decay of CT state with a rate constant $k_{\mathrm{CT}}$.

The rate equations would be:

7)

$$
\frac{d S}{d t}=G(t)-k_{s} \cdot S-\gamma_{s s} \cdot S^{2} ; \quad G(t)=k_{x} \cdot I_{0} \cdot e^{-\frac{1}{2} \cdot\left(\frac{t}{T s}\right)^{2}}
$$

pulse shape $x$ absorption coefficient $k_{x ;}$ time is measured in ps.

8)

$$
\frac{d\left[C T_{i}\right]}{d t}=\eta \cdot \gamma_{s s} \cdot[S]^{2}-k_{C T} \cdot\left[C T_{i}\right]
$$

(9) ... from (7); $\mathrm{I}^{0.5}<[\mathrm{S}]<\mathrm{I}$, depending on exciton concentration.

(10) from (8); $[\mathrm{CT}] \propto[\mathrm{S}]^{2}$; therefore $\mathrm{I}<[\mathrm{CT}]<\mathrm{I}^{2}$.

The (e - CT) mechanism is not favored because the photon concentration is many orders of magnitude greater than that of the free electron concentration. In addition, the (e - CT) process would give a light intensity dependence varying between 1.5 and 2.5 , with the 2.5 value appearing when the $\gamma_{a s} \mathrm{~S}^{2}$ contribution was relatively small compared with the $\mathrm{k}_{\mathrm{f}} \mathrm{S}$ contribution in Eq. (7). This however, is not the case; the $\gamma_{s e} \mathrm{~S}^{2}$ contribution is major $[11,12]$. 
This leaves the photon $+\mathrm{CT}_{1}$ mechanism. Using equation (4), which shows that the photoemission process depends on the product of the photon and $\mathrm{CT}_{\mathrm{i}}$ concentrations, and equation (10), it follows that

(11) $I^{2}<[h v]\left[C T_{i}\right]<I^{3}$.

The observed dependence of $\mathrm{I}^{2.4}$ is due to a greater effect of the singlet-singlet annihilation, which should be the case:

Taking $\mathrm{S}_{\max }=10^{19} / \mathrm{cm}^{3}$ as calculated from the light intensity, absorption coefficient, and pulse shape, and the values $\mathrm{k}_{\mathrm{s}}=5 \times 10^{9} \mathrm{~s}^{-1}, \gamma_{\mathrm{ss}}=10^{-7} \mathrm{~cm}^{3} \mathrm{~s}^{-1}$, and $\eta=0.01-1$ at $4.6 \mathrm{eV}$ [13], the only variable is $\mathrm{k}_{\mathrm{CT}}$. The range of values for $\eta$ and the value of $\sigma$ are not important for determining the shape of the curve that is shown in Fig. 1.

Equations (7) and (8) were solved numerically, excluding diffusion, and the fit between the calculated curve and the data is shown in Fig. 1. The deduced value for $\mathrm{k}_{\mathrm{CT}}$ was $5 \times 10^{10} \mathrm{~s}^{-1}$. However, electron emission takes place from a layer 10 - 15A deep, so at the present stage, we cannot attribute our measured lifetime to that of the charge-transfer (CT) state in the bulk, because in our mathematical analysis, we omitted the possible role of surface quenching of excited states. We have no independent data that quantify this effect, so by omitting surface quenching, we are left with a lower bound on the lifetime; the lifetime of the CT exciton in the bulk must be longer, but it is probably less than 100 ps, based on preliminary quenching rates.

The data in the time region -50 to -200 ps are not accounted for adequately by the theoretical curve. This slight deviation is not well understood at present, but does not contribute in a major way to the key experimental criteria. However, it points up the ability of this technique to pick up additional structure. Also, the use of the standard high vacuum 
photoemission apparatus should reveal more detailed information about the excited states involved in photoemission.

One interesting observation that must be made is that the light intensity dependence seems to rule out an important role for direct generation of CT states by the $3.5 \mathrm{eV}$ photon. This would imply that the efficiency of carrier generation at $3.5 \mathrm{eV}$ (laser energy) is so small that the bimolecular process in equation (8), coupled with the high ionization efficiency at $4.6 \mathrm{eV}$ (due to singlet-singlet fusion) is the dominant ionization mechanism.

This work was supported by the DOE Grant \# DEFG0286-ER60405. Acknowledgement is made of valuable discussions with Olof B. Widlund, Howard Fink, and Charles E. Swenberg. 
[1]. R. Voltz in "Internationai Disçussion of Progress and Problems in Contemporary Radiation Chemistry" (Ed. I. Santar) Academia, Prague, 1971, p. 160.

[2]. E.J. Bowen, E. Mikiewicz and F.W. Smith, Proc. Phys. Soc. (London), 1949, A62, 26.

[3]. M. Pope, J. Burgos, J. Giachino, J. Chem. Phys. 1965, 43, 3367.

L. Sebastian, G. Weiser, H. Bassler, 1985, 61, 125.

[4]. L. Altwegg, M. Pope, S. Arnold, Wm. Y. Fowlkes, M.A. Hamamsy, Rev. Sci. Instr., 1982, $53,332$.

[5]. T. Hirooka, K. Tanaka, K. Kuchitsu, M. Fujihara, H. Inokuchi, Y. Harada, Chem. Phys. Lett., 1973, 18, 390.

[6]. H. Muller, H. Bassler, J. Lumin., 1976, 12/13, 259.

[7]. Y. Tomkiewicz, R.P. Groff, P. Avakian, J. Chem. Phys., 1971, 54, 4504.

[8]. L. Sebastian, G. Weiser, H. Bassler, Chem. Phys., 1981, 61, 125.

[9]. R.R. Alfano, S.L. Shapiro, M. Pope, Opt. Commun., 1973, 9, 391.

[10]. K. Mizuno, A. Matsui, G.J. Sloan, J. Phys. Soc. (Jpn.), 1984, 53, 2799.

A. Bree, L.E. Lyons, J. Chem. Soc., 1960, 5206.

[11]. A.J. Campillo, R.C. Hyer, S.L. Shapiro, C.E. Swenberg, Chem. Phys. Lett., 1977, 48, 495.

[12]. F. Heisel, J.A. Miehe, M. Schott, B. Sepp, Chem. Phys. Lett., 1976, 43, 534.

[13]. E.A. Silinsh "Organic Molecular Crystals", Springer- Verlag, Berlin, 1980, p. 132. 


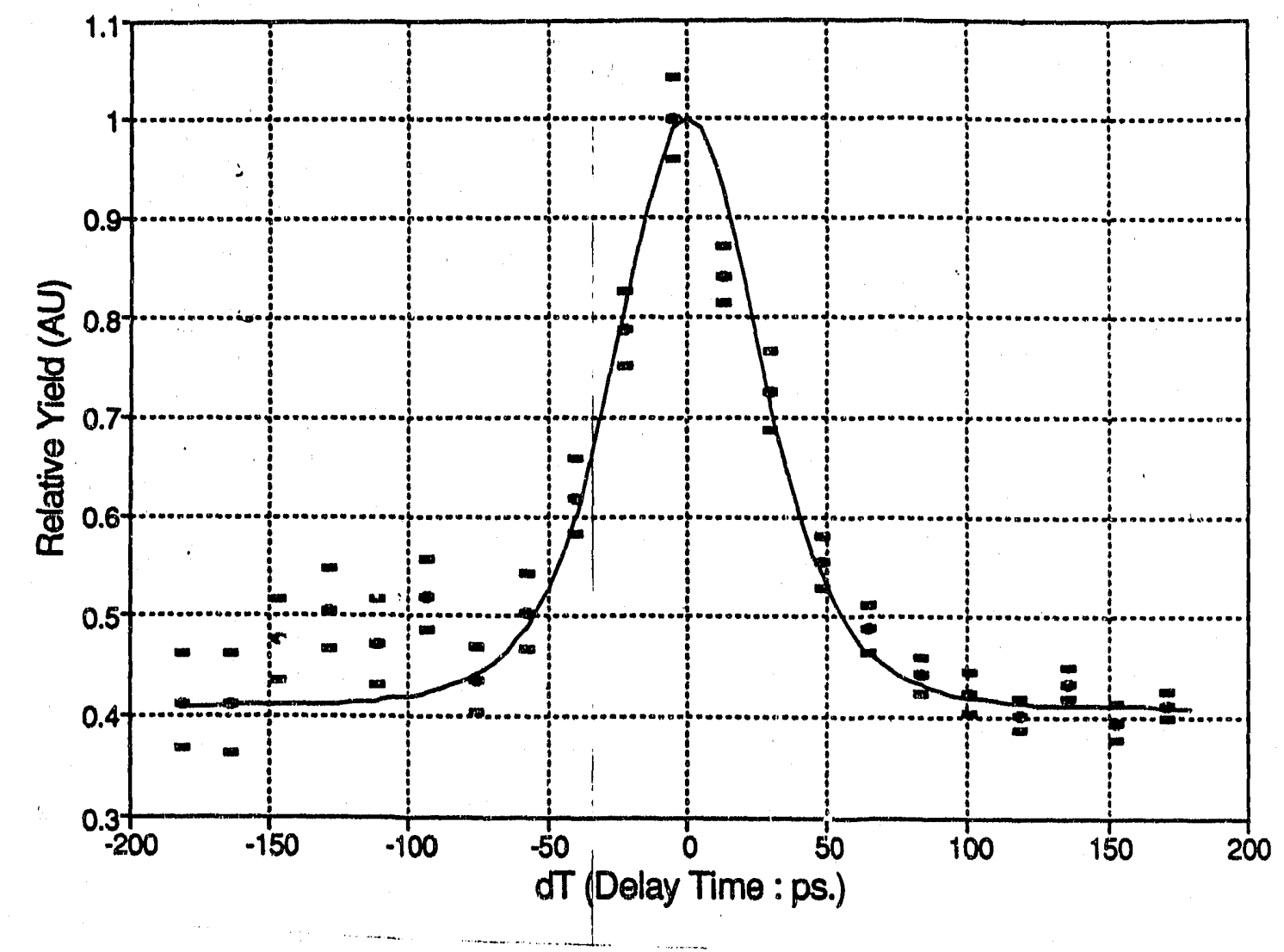

Figure 1. Time-resolved multi-step photoemission yield from tetracene single crystal as a function of the delay time between the prompt and delayed light pulse. The protnpt and delayed light pulses are interchangeable. Excitation is by the $355 \mathrm{~nm}$ harmonic of the laser, the pulse width of which is 35 ps FWHM. The calculated lifetime of the charge-transfer state is 20 ps. See text for additional details. 


\section{PUBLICATIONS ACKNOWLEDGING THIS GRANT (DE-FGO2-86ER60405)}

(July 1, 1991 - August 31, 1992)

1. "Applications of luminescence techniques in studies of polycyclic carcinogen-nucleic acid interactions." N.E. Geacintov and S.K. Kim, in: Practical Spectroscopy Series, Vol. 12: Luminescence Techriques in Chemical and Biochemical Anabysis. (W.R.G. Baeyens, D.D. Keukeleire, and K.K. Korkidis), Marcel Dekker, Inc., New York, pp. 317-339 (1991).

2. "Structures of the ( +$)$ and (-)-trans-anti-BPDE addlucts to guanine-N2 in a duplex dodecamer." S.B. Singh, B.E. Hingerty, U.C. Singh, J.P. Greenberg, N.E. Geacintov and S. Broyde, Cancer Res., (1991) 51, 3482-3492.

3. "Chemical, molecular biology, and genetic techniques for correlating DNA base damage induced by ionizing radiation with biological end-points." N.E. Geacintov and C.E. Swenberg, in: "Physical and Chemical Mechanisms in Mlolecular Radiation Biology.", M.N. Vartna and W.A. Glass, Eds., Plenum Press, pp. 4\$3-474 (1991).

3. "Characterization of the interaction of the radioprolectant 1-methyl-2-[2-(methylthio)-2-piperidinovinyl]-quinolinium indide with supercoiled DNA." C.E. Swenberg, S. Birke, and N.E. Geacintov, Radiation Research, 127, 138-145.

4. "Photoinduced electron transfer in a covalent benzo[a]pyrene diol epoxide-2'-deoxyguanosine complex." L. Margulis, P.1F. Pluzhnikov, B. Mao, V.A. Kuzmin, Y.J. Chang, T.W. Scott and N.E. Geacintov (1991), Chem. Phys. Lett. 187, 597-603.

5. "Dependence of conformations of benzo[a]pyrene diol epoxide-DNA adducts derived from stereoisomers of different tumorigenicities on base sequince. " C.J. Roche, A.M. Jeffrey, B. Mao, A. Alfano, S.K. Kim., V. Ibanez and N.E. Geacintov, Chem. Res. Toxicol. 4, (1991), 311-317.

6. "Spectroscopic characteristics and site 1/site II classification of cis and trans benzo|[a]pyrene diolepoxide enantiomer-guanosine adducts in oligonucleotides and polynucleotides." N.E. Geacintov, M. Cosman, B. Mar, A. Alfano, V. Ibanez and R.G. Harvey (1991) Carcinogenesis 12, 2099-2018.

7. "Solution conformation of the major adduct between the carcinogen (+)-antibenzola]pyrene diol epoxide and DNA." M. Cosman, C. de los Santos, R. Fiala, B.E. 
Hingerty, S.B. Singh, V. Ibanez, L.A. Margulis, D. Live, N.E. Geacintov, S. Broyde and D.J. Patel (1992) Proc. Natl. Acad. Sci. (USA) 89, 1914-1918.

8. "Influence of benzo[a]pyrene diol epoxide chirality on solution conformations of DNA covalent adducts: the (-)-trans-anti-[BP]G.C adduct structure and comparison with the (+)trans-anti-[BP]G.C enantiomer. C. de los Santos, M. Cosman, B.E. Hingerty, V. Ibanez, L.A. Margulis, N.E. Geacintov, S. Broyde and D.J. Patel (1992) Biochemistry 31, 52455252.

9. "Photoinduced electron transfer and fluorescence mechanisms in covalently linked polynuclear aromatic nucleotide complexes." N.E. Geacintov, B. Mao, L.L. France, R. Zhao, J. Chen, T.-M. Liu, N.-Q. Ya, L.A. Margulis, and J.C. Sutherland (1992), S.P.I.E. Proceedings, Time-Resolved Laser Spectroscopy in Biochemistry III, Vol. 1640, 774-783.

\section{IN PRESS (8/30/92)}

10. "High resolution gel electrophoresis methods for studying sequence-dependence of radiation damage and effects of radioprotectants in deoxyoligonucleotides." B. Mao, C.E. Swenberg, Y. Vaishnav and N.E. Geacintov (1992) in: Biological Effects and Physics of Solar and Galactic Solar Radiation, Eds. C.E. Swenberg, G. Homeck, and E.G. Stassinopoulos, Proceedings of NATO-ASI Conference, Armacao de Pera, Portugal, October 1991. Plenum Press, New York, 1992.

11. "Direct synthesis and identificauion of benzola]pyrene diol epoxide-deoxyguanosine binding sites in modified oligodeoxynuclentides. B. Mao, L.A. Margulis, B. Li, V. Ibanez, H. Lee, R.G. Harvey and N.E. Geacintov (1992) Chem. Res. Toxicol. 0, 000-000.

12. "Identification and quantitative detection of isomeric benzo[a]pyrene diolepoxide-DNA adducts by low-temperature conventional fluorescence methods." R. Zhao, T.-M. Liu, S.K. Kim, M.C. McLeod and N.E. Geacintov (1992) Carcinogenesis 13, 000-000.

13. "ps-Spectroscopy of excited states based on non-linear electron photoemission." A. Durandin, T.-M. Liu, M. Pope, S.-C. Sheu, and N.E. Geacintov, J. Phys. Chem., submitted. 

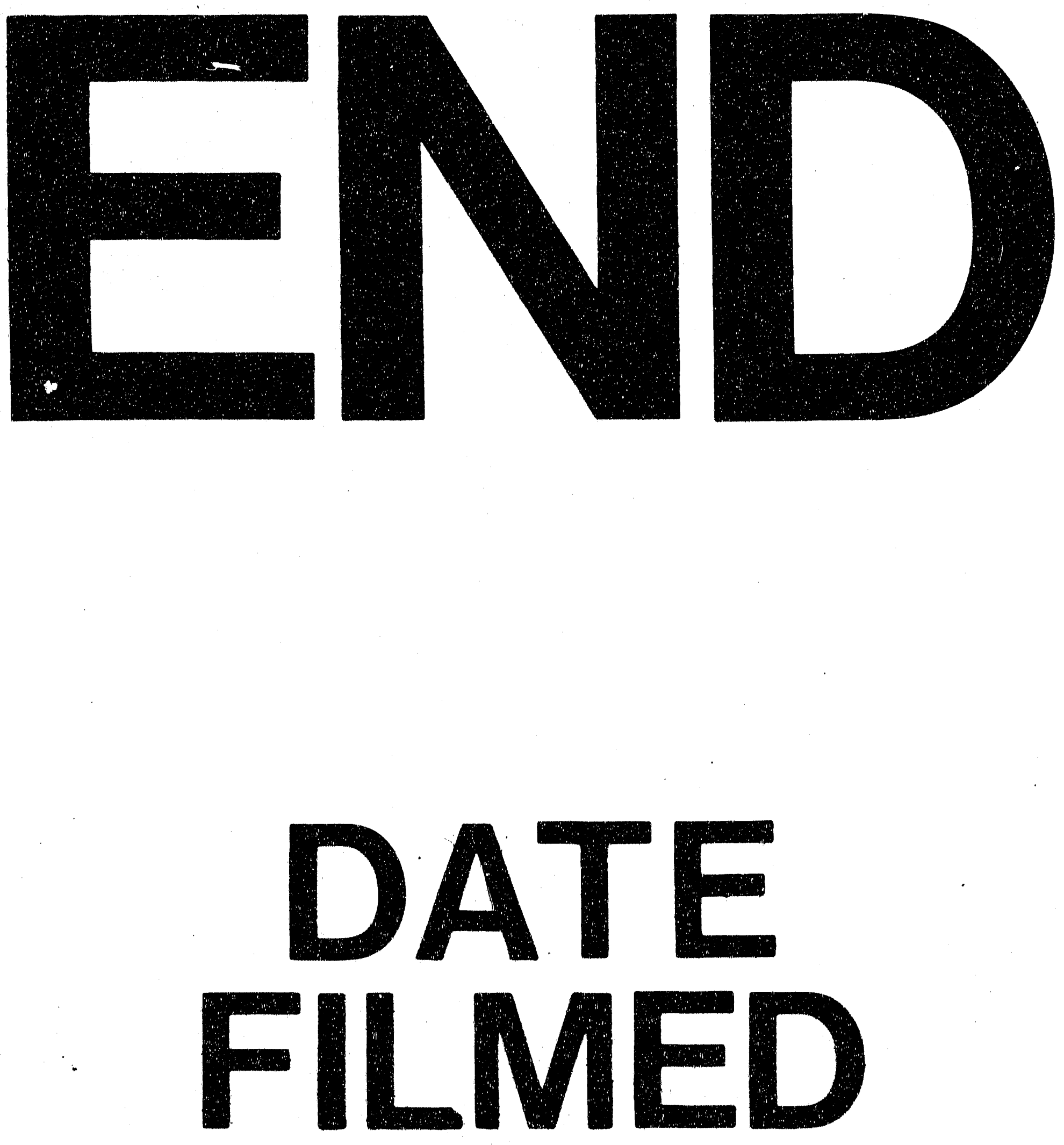

事

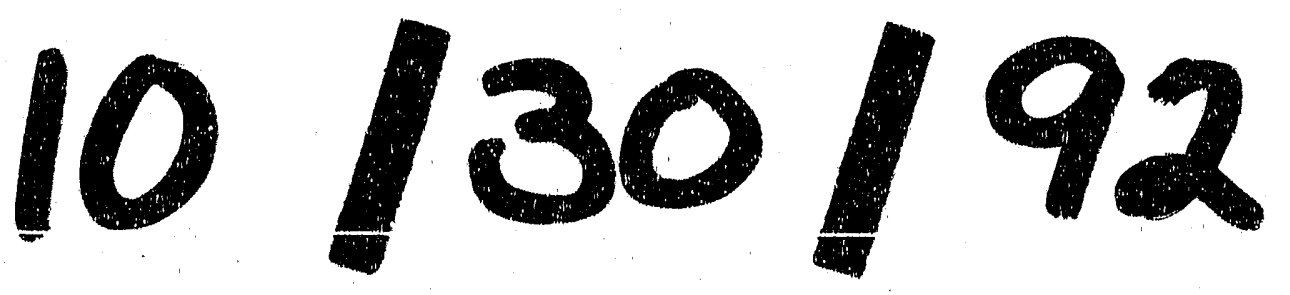


